\title{
Laparoscopic management of nonpalpable testis: 5 years' experience at Dhaka Shishu (Children) Hospital
}

\begin{abstract}
Introduction: Cryptorchidism or undescended testis is one of the most common genital disorders of boy. Now a day's laparoscopy has been widely used for the diagnosis and treatment of non-palpable testis. This study was done to evaluate the last five years' experience of laparoscopic management of non palpable testis at Dhaka Shishu (Children) Hospital.

Methods: This retrospective study was done from July 2012 to June 2017. The patients between the ages of 9 months to 16 years who had diagnostic laparoscopy for non palpable testes were included in the study. Physical examination results, preoperative diagnosis, a geat surgery, laparoscopic and inguinal exploration findings, surgical procedures, results and follow up findings were evaluated.

Results: Total 135 preoperatively diagnosed non pal pablete testes in 113 patients were managed laparoscopicaly. Mean age was $2.8 \pm 2.3$ years. In $66(48.8 \%)$ cases, laparoscopic examination followed by inguinal exploration was performed. Sixty nine $(51 \%)$ testes were found within the abdomen. Of those staged Fowler-Stephens procedure performed in 16 and in 49 cases $(36.3 \%)$ laparoscopic assisted single stage orchidopexy was done. A mean follow up period was 21 months. 52(80\%) of 54 testes of laparoscopic orchidopexy, had symmetrical testicular growth.

Conclusion: Laparoscopic approach is a reliable, useful and safe method for management of non palpabletestes. Its diagnostic uses obviate the unnecessary preoperative imaging studies, in guino-scrotal explorations to locate the accurate position of testes and help to decide the treatment options. The rapeuticroles of laparoscopy on mobilization of vas and testicular vessels and staged Fowler- Stephens procedures also very effective
\end{abstract}

Keywords: laparoscopy, orchidopexy, nonpalpable testis
Volume 8 Issue 3 - 2018

\author{
Kazi Md Noor-ul Ferdous,' Md Samiul \\ Hasan, ${ }^{2} \mathrm{KH}$ Ahasanul Kabir, ${ }^{2}$ Md Abdul Aziz,3 \\ M Kabirul Islam ${ }^{4}$
}

'Assistant Professor, Department of Neonatal Surgery, Division of Pediatric Surgery, Bangladesh Institute of Child Health and Dhaka Shishu (Children) Hospital, Bangladesh

${ }^{2}$ Registrar, Department of Minimally Invasive Surgery, Division of Pediatric Surgery, Bangladesh Institute of Child Health and Dhaka Shishu (Children) Hospital, Bangladesh

${ }^{3}$ Professor and Head, Department of Pediatric Urology, Division of Pediatric Surgery, Bangladesh Institute of Child Health and Dhaka Shishu (Children) Hospital, Bangladesh ${ }^{4}$ Professor and Head, Department of Neonatal Surgery, Division of Pediatric Surgery, Bangladesh Institute of Child Health and Dhaka Shishu (Children) Hospital, Bangladesh

\section{Correspondence: Kazi Md Noor-ul Ferdous, Assistant Professor, Department of Neonatal Surgery, Division of Pediatric Surgery, Bangladesh Institute of Child Health and Dhaka Shishu (Children) Hospital, Bangladesh, Emailkmnferdous@gmail.com}

Received:JMay 04, 2018| Published: June 26, 2018

\section{Introduction}

Cryptorchidism or undescended testis is one of the most common genitourinary disorders in young boys, where the testis can't be reached at the bottom of the scrotum. ${ }^{1} 3-5 \%$ of full termand18$45 \%$ ofpre-termnewborn boys are born with either unilateral or bilateral undecided testes. The prevalence drops to $1-2 \%$ by three months of age and $0.8 \%$ will still have cryptorchidism attend of 1 years. ${ }^{2-4}$ Smolko et al., ${ }^{5}$ reported that $20 \%$ of undescended testes are clinicallynonpalpable. ${ }^{5}$ The non palpable testis can be non-present, atrophic, or have a failure to descend and be found in ahighscrotal, inguinal, orintra-abdominal location. Most of the literatures report that approximately 20-40\%ofnon-palpabletestesareintraabdominalinlocation. ${ }^{6}$ Localization of the Nonpalpable testis is a significant problem in pediatric age group. The diagnostic methods are Ultra sonography, CT scan, MRI and laparoscopy have been used to locate non palpable testis. ${ }^{7}$ In a case with Nonpalpable testis, the classical approach was in guinal exploration, if testis found then orchiopexy. If testis cannot be found, then the procedure is preceded with open abdominal exploration. ${ }^{8}$ But, unplanned groin exploration may be detrimental to the outcome of surgery and sometime fruitless. ${ }^{9}$ Use of laparoscopy was firstly recommended by Cortesietal in1976 to locate non palpableundescended testes and laparoscopic orchidopexy was firstly performed by Jordan et al., in $1992 .{ }^{8}$ Nowadays, laparoscopic procedure is a gold standard in the management of patients with a Nonpalpable testis for localization and to plan subsequent surgical management in many centers. ${ }^{10}$ Wide screen behereour institutional experience with laparoscopic management of Nonpalpable testes in children over the last 5years.

\section{Materials and methods}

We retrospectively studied there cords between July 2012 and June 2017 in the Division of Pediatric Surgery, Dhaka Shishu (children) Hospital, Dhaka. Data of all patients between 9 months to16years of age who underwent laparoscopic management for Nonpalpable testis either unilateral or bilateral testes were analyzed. Physical examination findings, age at surgery, US reports, laparoscopic, and inguinal exploration findings, short, and long-term follow up and out comes of orchidopexy were evaluated. The diagnosis of Nonpalpable testis was reconfirmed by physical examination repeated under general anesthesia. Diagnostic laparoscopy was performed in all non palpable test is. Laparoscopic findings and were noted accordinglyAbsence of testicular vessels and vas deferens as agenesis. Vanishing testis noted as when spermatic vessels or vas found blind ending. If there was no testicular tissue, only remnants present- Atrophic testis. Entrance of was and testicular vessels into the internal inguinal ring 
with or without directly seeing the testis noted as canalicular testis. Abdominal testis was that, when it was found between the lower pole of kidney and the ipsilateral internal inguinal ring. Peeping testis was located primarily in intra-abdominal position, can introduce itself into the inguinal canal due to the intra-abdominal pressure augmentation during the laparoscopic procedure. It usually associated with patent process us vaginalis and returns to its original position by pressing the inguinal region externally.

The procedure is terminated in absence vas and vessels or intraabdominal vanishing testis. If testicular vessels were seen entering the internal in guinalring, inguinal exploration was performed. If laparoscopy revealed an intra-abdominal testis, laparoscopic orchiopexy was performed if low $(<2 \mathrm{~cm}$ from the internal inguinal ring). Laparoscopic staged Fowler- Stephens technique (FSO) if high ( $\geq 2 \mathrm{~cm}$ from the internal inguinal ring), or laparoscopic or chiectomy and histological examination if atrophic. All patients were followed post-operatively at 1 week, 3 weeks, and 6 months thereafter for 2 years. The variables included: surgical it infections, post-operative testicular location, and testicular size, measured at the time of surgery and compared to the normal contralateral testis on follow-up. Data were collected in a structured form and analyzed. Results were presented as mean \pm standard deviation for quantitative variables and numbers (percentages) for qualitative variables.

\section{Results}

Between July 2012 and June 2017, a total of 583 boys with undecided testes were operated in our center. Total 135 preoperatively diagnosed non palpability testes in 113 patients were managed laparoscopicaly. Mean age was $2.8 \pm 2.3$ years (ranged 9.6 months to 11.3 years). Ninety one testes were unilateral of which 37 right-sided (32.7\%), 54 left sided (47.8\%) and 22 bilateral cases (19.4\%). (Figure 1) (Figure 2) The vas and vessels of 65 tests was entered into the deep inguinal ring and rest $69(51 \%)$ testes were found within the abdomen. The procedures performed according to the position and condition of the testis after diagnostic laparoscopy shown in (Table 1). There was no operative mortality and morbidity in our series. Mean follow up period was 21 months (ranged from 8 months to 2.6 years). Position and size of the testis are $90 \%$ satisfactory in inguinal orchiedopexy and more than $80 \%$ in laparoscopic orchiedopexy. Finding of follow up shown in Table 2.

Table I Procedures performed according to the position/condition of the testis after laparoscopy

\begin{tabular}{|c|c|c|}
\hline \multicolumn{2}{|c|}{ Position/condition of the testis } & \multirow{2}{*}{$\begin{array}{l}\text { Procedures performed } \\
\text { Inguinal Exploration }\end{array}$} \\
\hline Canalicular testis $(\mathrm{n}-6$ & & \\
\hline \multirow{2}{*}{$\begin{array}{l}\text { Closed internal ring } \\
-19-14 \%\end{array}$} & Vanishing (13) & -- \\
\hline & Atrophied- 6 (5.9\%) & Orchiectomy and histopathology \\
\hline \multirow{2}{*}{$\begin{array}{l}\text { Patent process us } \\
\text { vaginalis }-47 \text { (34.8\%) }\end{array}$} & Vanishing (8) & -- \\
\hline & Normal - $39(28.9 \%)$ & Inguino-scrotal Orchiedopexy \\
\hline $\begin{array}{l}\text { Intra-abdominal testis } \\
(\mathrm{n}-69)\end{array}$ & & Laparoscopic \\
\hline Atrophied - 4 (2.9\%) & & Orchiectomy and histopathology \\
\hline Low - 49 (36.3\%), & & Orchiedopexy \\
\hline High - 16 (11.8\%) & & $\begin{array}{l}\text { Staged Fowler-Stephens } \\
\text { Orchiedopexy }\end{array}$ \\
\hline
\end{tabular}

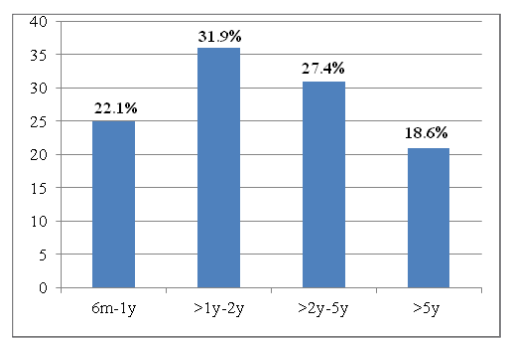

Figure I Age distribution.

Table 2 Position and condition of testis at follow up according to the procedures performed. $(n=100)$

\begin{tabular}{|c|c|c|c|c|}
\hline \multirow{2}{*}{$\begin{array}{l}\text { Procedure } \\
\text { Inguinal } \\
\text { Exploration and } \\
\text { orchiedopexy } \\
-(39)\end{array}$} & \multicolumn{2}{|c|}{ Position of the testis } & \multicolumn{2}{|c|}{ Condition of the testis } \\
\hline & $\begin{array}{l}\text { Within the } \\
\text { Scrotum }\end{array}$ & $\begin{array}{l}\text { At the } \\
\text { neck of the } \\
\text { scrotum }\end{array}$ & $\begin{array}{l}\text { Acceptable } \\
\text { growth }\end{array}$ & $\begin{array}{l}\text { Reduced } \\
\text { in size }\end{array}$ \\
\hline & 35 & 4 & 35 & 4 \\
\hline \multicolumn{5}{|c|}{ Laparoscopic Orchiedopexy } \\
\hline Single stage -(49) & 42 & 7 & 43 & 6 \\
\hline $\begin{array}{l}\text { Staged Fowler- } \\
\text { Stephens - (16) }\end{array}$ & 10 & 6 & 11 & 5 \\
\hline
\end{tabular}

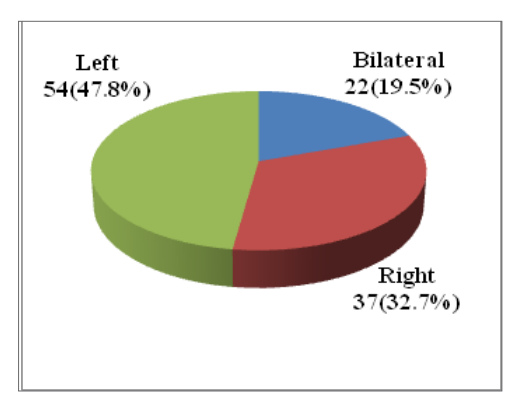

Figure 2 Site distributions.

\section{Discussion}

Cryptorchidism or undecided testis is one of the most common genitourinary disorders in young boy. The mechanism of testicular descends yet not fully understood. It occurs during two different gestational stages, during 8-15 and 25-35 intrauterine weeks. Failure of the first phase of descend is rarer than that of the second phase and result in intra-abdominal testis. ${ }^{11}$ The treatment of undecided testicles is mandatory due to the higher risk of infertility and malignancy than normal adult. ${ }^{12,13}$ The management of boys with palpable undecided testes has been standardized, but the rearen of or mal guidelines for the management of boys with impalpable testes. ${ }^{14}$ The management of impalpable testis was challenging and controversial before the era of laparoscopic surgery. To pre-operative localization of testis different imaging techniques like, including USG, CT scan and magnetic reason and cearteriography/venography had been described. However, none of them had $100 \%$ accuracy. Also, they were often expensive, required sedation and had potential radiation hazard. ${ }^{15,16}$ Laparoscopy is currently the most reliable diagnostic modality in the management of impalpable testes. It clearly shows the atomy and provides svisualin formation upon which a definitive decision can be 
based. It is not only provides a solution for diagnosis in localization of impalpable testis, but also is an essential therapeuticprocedureforintraabdominaltestis. ${ }^{16,17}$ The mean age of the patients during operation in our series was $2.8 \pm 2.3$ years, and it was higher than the suggested age for orchiedopexy in most literatures. It was found that post-natal testicular descent was rarely possible beyond 3 months. The incidence of crypt orchidism remains relatively constant fromlyear old until adult hood. Beyond second year of life, non-operated undecided testes will show histological changes in the somniferous tubules. ${ }^{16}$ A Significant proportion of patients (46\%) were older than 2 years. It due to lack of awareness and the low socio-economic condition of the country and difficult to access to tertiary health care in our country. Tang PMY et al identified late referral of patients to the surgical clinic was the main cause of delay in presentation ${ }^{16}$. In the management of impalpable testis, the use of laparoscopy is essential, both in diagnosis and treatment. It provides direct vision to intra-peritoneal structures with magnified view. The location and morphology of testis can be accurately determined, and further surgical procedures canbeplanned ${ }^{16}$. In our series, 66testes $(48.8 \%)$ were found descended beyond the deep in guinalring. These were diagnosed laparoscopicaly and then inguinal exploration was performed. Orchidopexy was done on normal on near normalized can aliculartestis whereas orchidectomy was done on atrophied and vanishing testis. Laparoscopic intervention plays key role in the treatment for intra-abdominal testes. Laparoscopic mobilization of vas and testicular vessels allows dissection of the short-length testicular vessels from retro peritoneum, which facilitates further mobilization of testisinsubsequentinguinalorchidopexy. ${ }^{18}$ In our series, 4(2.9\%) intra-abdominal atrophic testes were removed laparoscopicaly. Mobilization of vas and testicular vessels followed by in guinal orchiedopexy was performed laparoscopicaly in 49 cases $(36.3 \%)$, of lower intra-abdominal testis. Highintra-abdominal testis was found in 16 cases $(11.8 \%)$, where the testicular vessels were too short such that one stage mobilization of test is to scrotum was impossible.

Laparoscopic division of testicular vessels was performed. Fowler and Stephens in 1959 first described the concept of ligation of testicular artery in orchidopexy. The principle of this procedure is based on the anatomical fact that the test is has triple blood supply; namely testicular artery, cremasteric artery and the artery to the vas. Ligation of one vessel will not result in testicular is chaemia; instead it can promote the development of collateral circulation of testis. Caldamone and Amaral further popularized the two stage laparoscopic Fowler-Stephens orchiedopexy. The testicular artery is ligated in stage one operation, and the testis will be mobilized laparoscopicaly to scrotal position based on them as alerter in second stage operation, which was performed6to9monthslater. ${ }^{19}$ Tang PMY et al suggested that, fruit less inguinal exploration for high intra-abdominal testis may compromise the cremasteric vassal blood supply to the testis, and hinder futureFowler-Stephensprocedure ${ }^{16}$. In our series, we could manage 69 cases $(51 \%)$ of intra-abdominal testis laparoscopicaly without inguinal exploration. In successful orchidopexy, the testis was brought to scrotum without post-operative atrophy. During post operative follow up, 51 testes $(78.5 \%)$ of our study had symmetrical testicular growth out of 65 laparoscopic orchiedopexy. The success rate of operation was varies from $74-91.1 \%$ in the literature ${ }^{20}$ It is not only important to protect the vasculature of testis during operation, but also to obtain sufficient length for orchiedopexy. Thus, judicious use of laparoscopy and meticulous surgical techniques are the cornerstone of success in operationsforimpalpabletestes. ${ }^{16}$

\section{Conclusion}

Laparoscopic approach is a reliable, useful and safe method form an agement of non palpable testes. Its diagnostic uses obviate the unnecessary preoperative imaging studies, inguino-scrotal explorations to locate the accurate position of testes and help to decide the treatment options. Therapeutic roles of laparoscopy on mobilization of vas and testicular vessels and staged Fowler- Stephens procedures also very effective.

\section{Acknowledgments}

None.

\section{Conflict of interest}

The author declares there is no conflict of interest.

\section{References}

1. Mohta A. Cryptorchidism. What's New? Indian Paediatrics. 2004;41:1019-1023.

2. Scorer CG, Farrrington HG. Congenital deformities of the testis and epididymis. London: Butter worths; 1971.

3. Sijstermans K, Hack WW, Meijer RW, et al. The frequency of undescended testis from birth to adulthood: a review. Int J Androl. 2008;32(1):1-11.

4. Gearhart JP, Jeffs RD. Diagnostic maneuvers in cyrptorchidism. Sernin Urol. 1988;6(2):79-83.

5. Smolko MJ, Brock WA, Kaplan GW. Location and fate of the non palpable testis in children. JUrol1983;129(6):1204-1206.

6. Castillo-Ortiz J, Muñiz-Colon L, Escudero K, et al. Laparoscopy in the Surgical Management of the Non-Palpable Testis. Front Pediatr. 2014;2:28.

7. Kanemoto K, Hayshi Y, Kojima Y, et al. Accuracy of ultrasonography and magnetic resonance imaging in the diagnosis of nonpalpable testis. International Journal of Urology. 2005;12(7):668-672.

8. Cortesi N, Ferrari P, Zambarda E, et al. Diagnosis of bilateral abdominal cryptorchidism by laparoscopy. Endoscopy.1976;8(1):33-34.

9. Khalid I, Ashour M, Afifi ME. Laparoscopy in the management of impalpable testis: Series of 64cases. World Journal of Surgery. 2009;33(7):1514-1519.

10. Erdogan C, Bahadır B, Taşkınlar H, et al. Laparoscopic management and its out comes in cases with non palpabletestis. Turk J Urol. 2017;43(2):196201.

11. Hutson JM, Clarke MCC. Current management of the undescended testicle. Semin Pediatr Surg. 2007;16(1):64-70.

12. Garner MJ, Turner MC, Ghadirian P, et al. Epidemiology of testicular cancer: an overview. Int $J$ Cancer.2005;116(3):331-339.

13. Lee PA, O'leary LA, Songer NJ, et al. Paternity after unilateral cryptorchidism: a controlled study. Pediatrics.1996;98(4):676-679.

14. C Esposito, AA Caldamone, A Settimi, et al. Management of boys with non palpable undescended testis. Nature Clinical Practice Urology. $2008 ; 5: 252-260$.

15. Hrebinko RL, Bellinger MF. The limited role of imaging techniques in managing children with undescended testes. J Urol. 1993;150(2Pt1):458 460. 
16. Tang PMY, Leung MWY, Chao NSY, et al. Use of Laparoscopy in the Management of Impalpable Testis in Children. HKJ Paediatr (newseries). 2009;14:172-176.

17. SY Tennenbaum, SE Lerner, IM McAleer, et al. Preoperative laparoscopic localization of the nonpalpable testis: a critical analysisofa10- year experience. Journal of Urology.1994;151(3):732-734.

18. Leung MW, Chao NS, Wong BP, et al. Laparoscopic mobilization of testicular vessels: an adjunctive step in orchidopexy for impalpable and redo undescended testis in children. Pediatr Surg Int. 2005;21(9):767-769.
19. Caldamone AA, Amaral JF. Laparoscopic stage2 Fowler- Stephens orchiopexy. J Urol.1994;152(4):1253-1256.

20. Docimo SG. The results of surgical therapy for cryptorchidism: a literature review and analysis. J Urol. 1995;154(3):1148-1152. 